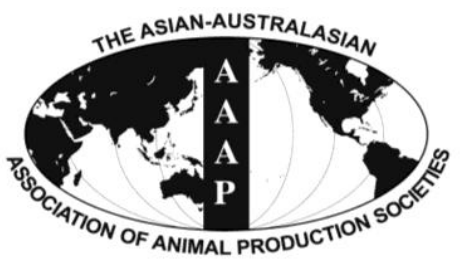

Open Access

Asian Australas. J. Anim. Sci.

Vol. 27, No. 11 : 1652-1662 November 2014

http://dx.doi.org/10.5713/ajas.2014.14562

pISSN 1011-2367 elSSN 1976-5517

\title{
The Influence of Feed Energy Density and a Formulated Additive on Rumen and Rectal Temperature in Hanwoo Steers
}

\author{
Sangbuem Cho ${ }^{1,2, a}$, David Tinotenda Mbiriri ${ }^{1, a}$, Kwanseob Shim ${ }^{3, a}$, A-Leum Lee ${ }^{1}$, Seong-Jin Oh $^{1}$, Jinho Yang ${ }^{1}$, \\ Chaehwa Ryu ${ }^{1}$, Young-Hoon Kim ${ }^{1}$, Kang-Seok Seo ${ }^{4}$, Jung-Il Chae ${ }^{5}$, Young Kyoon $\mathrm{Oh}^{6}$, and Nag-Jin Choi ${ }^{1}$ * \\ ${ }^{1}$ Department of Animal Science, Chonbuk National University, Jeonju 561-756, Korea
}

\begin{abstract}
The present study investigated the optimum blending condition of protected fat, choline and yeast culture for lowering of rumen temperature. The Box Benken experimental design, a fractional factorial arrangement, and response surface methodology were employed. The optimum blending condition was determined using the rumen simulated in vitro fermentation. An additive formulated on the optimum condition contained $50 \%$ of protected fat, $25 \%$ of yeast culture, $5 \%$ of choline, $7 \%$ of organic zinc, $6.5 \%$ of cinnamon, and $6.5 \%$ of stevioside. The feed additive was supplemented at a rate of $0.1 \%$ of diet (orchard grass:concentrate, $3: 7$ ) and compared with a control which had no additive. The treatment resulted in lower volatile fatty acid (VFA) concentration and biogas than the control. To investigate the effect of the optimized additive and feed energy levels on rumen and rectal temperatures, four rumen cannulated Hanwoo (Korean native beef breed) steers were in a $4 \times 4$ Latin square design. Energy levels were varied to low and high by altering the ratio of forage to concentrate in diet: low energy (6:4) and high energy (4:6). The additive was added at a rate of $0.1 \%$ of the diet. The following parameters were measured; feed intake, rumen and rectal temperatures, ruminal $\mathrm{pH}$ and VFA concentration. This study was conducted in an environmentally controlled house with temperature set at $30^{\circ} \mathrm{C}$ and relative humidity levels of $70 \%$. Steers were housed individually in raised crates to facilitate collection of urine and feces. The adaptation period was for 14 days, 2 days for sampling and 7 days for resting the animals. The additive significantly reduced both rumen $(\mathrm{p}<0.01)$ and rectal temperatures $(\mathrm{p}<0.001)$ without depressed feed intake. There were interactions $(\mathrm{p}<0.01)$ between energy level and additive on ruminal temperature. Neither additive nor energy level had an effect on total VFA concentration. The additive however, significantly increased $(\mathrm{p}<0.01)$ propionate and subsequently had lower acetate:propionate $(\mathrm{A} / \mathrm{P})$ ratios than non-additive supplementation. High concentrate diets had significantly lower $\mathrm{pH}$. Interactions between energy and additive were observed $(\mathrm{p}<0.01)$ in ammonia nitrogen production. Supplementation of diets with the additive resulted in lower rumen and rectal temperatures, hence the additive showed promise in alleviating undesirable effects of heat stress in cattle. (Key Words: Beef Cattle, Feed Additive, Heat Stress, Rectal Temperature, Rumen Temperature)
\end{abstract}

\section{INTRODUCTION}

High feed energy density is crucial during the fattening

\footnotetext{
* Corresponding Author: Nag-Jin Choi. Tel: +82-63-270-2579, Fax: +8263-270-2612, E-mail: nagjin@jbnu.ac.kr

${ }^{2}$ Animal Resources Research Center, Konkuk University, Seoul 143-701, Korea.

${ }^{3}$ Department of Animal Biotechnology, Chonbuk National University, Jeonju 561-756, Korea.

4 Department of Animal Science and Technology, Sunchon National University, Suncheon 540-742, Korea.

5 Department of Dental Pharmacology, Chonbuk National University, Jeonju 561-756, Korea

${ }^{6}$ Animal Nutrition and Physiology Division, National Institute of Animal Science, RDA, Suwon 441-706, Korea.

a These authors contributed equally to this work.

Submitted Jul. 25, 2014; Revised Sept. 22, 2014; Accepted Sept. 25, 2014
}

in beef cattle. High-energy feeds, however, can increase internal body temperature and may consequently result in heat stress. Consequences of heat stress can lead to economic losses particularly during the hot seasons (Williams et al., 2009). Providing shade and more water points can be strategies for reducing high heat load in cattle. However, these measures are applicable only in pastured herds and fewer options are available in feedlot cattle production. Altering energy density in feed and providing more by-pass nutrients have successfully reduced the metabolic heat load for beef and dairy cattle (Russell, 2007; Renadueau et al., 2012). It has been reported that heat reduction could be achieved by metabolic modulation such as altering volatile fatty acid (VFA) production in favor of higher propionate production (Gray and Ryan, 1989; Spears 
et al., 2004) and reducing deamination in the rumen (Renaudeau et al., 2012). Few attempts, however, have showed the effectiveness in reducing heat load by providing feed additives (Pompeu et al., 2011).

In the present study, we formulated a feed additive using protected fat, choline, yeast culture, cinnamon, organic zinc and stevioside. We hypothesized that providing an additive having features for increasing energy density and modulating nutrient metabolic pathways could lower body heat in cattle and result in lowering the risk of heat stress. There was a possible synergistic effect among three ingredients (protected fat, choline, and yeast culture) in modulating VFA production toward lowering heat production in the rumen using statistical method. Two experiments were conducted. In the first experiment, optimization of three ingredients to alter VFA production in in vitro rumen fermentation was performed. In the second experiment, a feeding study, we investigated the effect of supplementing the optimized additive in two diets varying in energy density (low and high energy densities) on dry matter intake, rumen fermentation parameters and rumen and rectal temperature.

\section{MATERIALS AND METHODS}

\section{Experiment 1}

Design of experiment for optimizing blend: The response surface method was employed to determine the optimum blend of ingredients in the additive. Six ingredients (choline, cinnamon, protected fat, stevioside, organic zinc, and yeast culture) were used and three of them (protected fat, choline, and yeast culture) were used as variables. Each variable was applied at three different levels. The rest of the ingredients were included at a fixed level. Inclusion levels were coded as $-1,0$, and 1 for low, medium and high levels, respectively. The Box Behnken design (Box and Behnken, 1960) was employed in the design of the experiment (DOE) and resulted in a total of 15 runs with three variables. Detailed configuration of DOE including coded and uncoded levels of each variables are presented in Table 1.

In vitro rumen fermentation: Rumen fluid was collected before morning feeding from two Hanwoo steers (Korean native beef breed, $350 \pm 20 \mathrm{~kg}$ of body weight) fitted with rumen cannulae. The steers were being fed a 50:50 ration of hay and a commercial concentrate diet twice a day (09:00 and 15:00 h). The collected rumen fluid was contained in thermo bottle and transported to the laboratory within an hour. The rumen fluid was strained through eight layers of cheese cloth and diluted at a ratio of 1:4 with McDougall solution ( $\mathrm{pH}$ 6.9) (McDougall, 1948). The strained rumen fluid-McDougall solution mixture was used as the inoculum. An aliquot $50 \mathrm{~mL}$ of inoculum was dispensed, under a stream of $\mathrm{CO}_{2}$, into each serum bottle containing $0.5 \mathrm{~g}$ of diet and different blends of variables according to DOE. The diet, which had been milled through a $1 \mathrm{~mm}$ sieve, was composed of commercial concentrate diet and orchard grass in ratio of $7: 3$. The chemical composition of the diet is shown in Table 2. Serum bottles were sealed with an aluminium cap and a rubber stopper before transferring them to an incubator at $39^{\circ} \mathrm{C}$. Fermentation parameters were determined at different incubation periods $(0,2,4,6,8$, 12 , and $24 \mathrm{~h}$ ). At the end of each incubation period, biogas production was measured by displacing a glass syringe.

Table 1. Box Behnken design for the evaluation of effects of protected fat, choline and yeast extract on in vitro rumen fermentation parameters

\begin{tabular}{|c|c|c|c|c|c|c|}
\hline \multirow{3}{*}{ Runs } & \multicolumn{6}{|c|}{ Variable } \\
\hline & \multicolumn{2}{|c|}{ Protected fat } & \multicolumn{2}{|c|}{ Choline } & \multicolumn{2}{|c|}{ Yeast } \\
\hline & Coded & Uncoded $(\%)$ & Coded & Uncoded $(\%)$ & Coded & Uncoded (\%) \\
\hline 1 & -1 & 0.01 & -1 & 0.0005 & 0 & 0.01 \\
\hline 2 & 1 & 0.1 & -1 & 0.0005 & 0 & 0.01 \\
\hline 3 & -1 & 0.01 & 1 & 0.01 & 0 & 0.01 \\
\hline 4 & 1 & 0.1 & 1 & 0.01 & 0 & 0.01 \\
\hline 5 & -1 & 0.01 & 0 & 0.0015 & -1 & 0.005 \\
\hline 6 & 1 & 0.1 & 0 & 0.0015 & -1 & 0.005 \\
\hline 7 & -1 & 0.01 & 0 & 0.0015 & 1 & 0.05 \\
\hline 8 & 1 & 0.1 & 0 & 0.0015 & 1 & 0.05 \\
\hline 9 & 0 & 0.02 & 0 & 0.0005 & -1 & 0.005 \\
\hline 10 & 0 & 0.02 & 1 & 0.01 & -1 & 0.005 \\
\hline 11 & 0 & 0.02 & -1 & 0.0005 & 1 & 0.05 \\
\hline 12 & 0 & 0.02 & 0 & 0.01 & 1 & 0.05 \\
\hline 13 & 0 & 0.02 & 0 & 0.0015 & 0 & 0.01 \\
\hline 14 & 0 & 0.02 & 0 & 0.0015 & 0 & 0.01 \\
\hline 15 & 0 & 0.02 & 0 & 0.0015 & 0 & 0.01 \\
\hline
\end{tabular}


Table 2. Nutritional content of experimental feed stuffs

\begin{tabular}{lcc}
\hline Items & Concentrate (\%) & Orchard grass (\%) \\
\hline $\mathrm{DM}$ & 89.81 & 89.28 \\
$\mathrm{CP}$ & 13.25 & 7.22 \\
$\mathrm{EE}$ & 4.04 & 1.64 \\
$\mathrm{CF}$ & 10.27 & 30.86 \\
$\mathrm{NDF}$ & $\mathrm{ND}$ & 58.25 \\
$\mathrm{ADF}$ & $\mathrm{ND}$ & 31.86 \\
Ash & 6.04 & 6.77 \\
Calorie (kcal) & 3.80 & 3.60
\end{tabular}

DM, dry matter; $\mathrm{CP}$, crude protein; EE, ether extract; $\mathrm{CF}$, crude fiber; $\mathrm{NDF}$, neutral detergent fiber; ND, Not determined; ADF, acid detergent fiber.

After measuring biogas, contents of the serum bottles were centrifugation was followed $\left(3,000 \mathrm{~g}, 20 \mathrm{~min}\right.$ at $\left.4{ }^{\circ} \mathrm{C}\right)$. The supernatant was stored at $-20^{\circ} \mathrm{C}$ for VFA analysis. Samples for VFA analysis were pre-treated by adding $0.2 \mathrm{~mL}$ of $25 \%$ (w/v) metaphosphoric acid for $1 \mathrm{~mL}$ of supernatant. The $\mathrm{pH}$ of rumen liquor was immediately measured using a $\mathrm{pH}$ meter. The VFAs were determined by chromatography (HP6809, Hewlett-Packard, Palo Alto, CA, USA) equipped with Econo-Cap EC-Wax column $(0.25 \mathrm{~mm}$ i.d. $\times 0.25 \mu \mathrm{m}$ film $\times 30 \mathrm{~m}$ length, Alltech, Nicholasville, KY, USA) according to Erwin et al. (1961).

\section{Experiment 2}

Animals and experimental design: The subjects in this experiment were four Hanwoo steers $(350 \pm 20 \mathrm{~kg}$ of body weight) fitted with rumen cannulae and housed individually in raised cages $(3 \mathrm{~m} \times 1.5 \mathrm{~m} \times 2.2 \mathrm{~m})$. The cages were enclosed in an environmentally controlled unit and the average relative humidity was $70 \%$. Ambient temperature was set at $30^{\circ} \mathrm{C}$. Steers were randomly assigned to four experimental diets in a $4 \times 4$ Latin square design. The treatments were formulated in a $2 \times 2$ factorial arrangement. The factors were energy levels and additive. Energy levels were varied by varying the ratio of orchard grass and concentrate diet. Orchard grass and concentrate were mixed in ratio of 6:4 for low energy diet and high energy was in ratio of $4: 6$. Additive treatments were denoted by giving superscript as with additive $\left(^{+}\right)$and without additive $\left(^{-}\right.$). Treatment diets therefore were; $6: 4^{-}, 4: 6^{-}, 6: 4^{+}$, and $4: 6^{+}$. Concentrate and orchard grass were same with the diets used in experiment 1 . Used additive was prepared according to formula optimized in experiment 1. Diets were formulated to meet the dietary requirements of Hanwoo beef cattle according to Korean Feeding Standard for Hanwoo. Each steer was fed $8 \mathrm{~kg}$ per day. Those receiving an additive were supplemented at a rate of $0.1 \%$ of diet. The additive contained choline, cinnamon, protected fat, stevioside, organic zinc and yeast culture. The daily ration was split into two feeding times; 09:30 and 17:30 h. Steers had free access to fresh water during the trial. Each experimental period consisted of 23 days. The first 14 days were for adaptation, 2 days for sampling and 7 days for resting the animals before the commencement of the next experimental period.

Sampling and measurements: Feed intake, feces and urine output were measured on a daily basis. Samples of rumen contents were collected $1 \mathrm{~h}$ before feeding and 2, 4, 6,8 , and $12 \mathrm{~h}$, respectively after the morning feeding on days 11 and 12 of the each experimental period. Rumen liquor was squeezed out from rumen contents samples and strained through four layers of cheese cloth. The $\mathrm{pH}$ of rumen liquor was immediately measured using a $\mathrm{pH}$ meter after which it was centrifuged $\left(3,000 \mathrm{~g}\right.$ for $10 \mathrm{~min}$ at $\left.4^{\circ} \mathrm{C}\right)$. Samples of the supernatant were stored in a freezer at $20^{\circ} \mathrm{C}$ until determination of ammonia nitrogen $\left(\mathrm{NH}_{3}-\mathrm{N}\right)$, and VFA. $\mathrm{NH}_{3}-\mathrm{N}$ was determined using spectrophotometry according to the method of Chaney and Marbach (1962). Briefly, $0.02 \mathrm{~mL}$ of culture supernatant were mixed with 1 $\mathrm{mL}$ of phenol color regent and $1 \mathrm{~mL}$ of alkali-hypochlorite reagent and then incubated at $37^{\circ} \mathrm{C}$ in a water bath for 15 min. Optical density was then determined at $630 \mathrm{~nm}$ using a spectrophotometer (Optizen, Daejeon, Korea). The VFAs were determined by chromatography according to Erwin et al. (1961).

Rumen and rectal temperature: An indwelling system which uses a temperature sensor (iButton, Maximum Integrated Products, Inc. Sunnyvale, CA, USA) placed in the ventral sac of the rumen was used. The sensor was inserted in the rumen $24 \mathrm{~h}$ prior to the first sampling day and then it was removed after $24 \mathrm{~h}$. Rectal temperature was measured $1 \mathrm{~h}$ before feeding and 2, 4, 6, 8, and $12 \mathrm{~h}$ after feeding, respectively using a digital thermometer (T-Tec data logger type 7, Temperature Technology, Adelaide, Australia). Before inserting the probe of the thermometer, the rectum was palpated to empty any faecal content. A lubricant was applied to the anus for the comfort of the animals.

\section{Statistical analysis}

In experiment 1 , construction of Box Behnken design, analysis of variance (ANOVA) with observed responses, response surface model fitting and calculation of optimum condition were performed using Minitab (version 16, State College, PA, USA) (Ryan, 2012). A student's t-test was employed for mean comparison in the verification experiment using SPSS (version 18, SPSS Inc., Chicago, IL, USA). In experiment 2 , data were analysed as a $4 \times 4$ Latin square using the general linear model procedure of SAS (9.2). The model included period, steer, and treatment. The treatment structure consisted of a $2 \times 2$ factorial arrangement, hence orthogonal contrasts were used to partition specific treatment effects. The following contrast statements were 
Table 3. Responses from in vitro rumen fermentation and their regression probability

\begin{tabular}{|c|c|c|c|c|c|c|c|c|}
\hline \multirow{3}{*}{ Run } & \multicolumn{7}{|c|}{ Responses at $24 \mathrm{~h}$ incubation } & \multirow{3}{*}{$\begin{array}{c}\text { Response at } 12 \mathrm{~h} \\
\text { Biogas } \\
(\mathrm{mL})\end{array}$} \\
\hline & \multirow{2}{*}{$\mathrm{pH}$} & \multicolumn{5}{|c|}{ Volatile fatty acid ${ }^{1}$ production $(\mathrm{mM})$} & \multirow{2}{*}{$\begin{array}{c}\text { Biogas } \\
(\mathrm{mL})\end{array}$} & \\
\hline & & $\mathrm{C} 2^{1}$ & $\mathrm{C} 3$ & $\mathrm{C} 4$ & $\mathrm{C} 5$ & Total & & \\
\hline 1 & 6.52 & 35.29 & 16.67 & 10.46 & 4.12 & 66.54 & 106 & 83 \\
\hline 2 & 6.55 & 33.43 & 16.63 & 10.84 & 4.04 & 64.94 & 93 & 78 \\
\hline 3 & 6.53 & 36.41 & 17.20 & 10.40 & 4.18 & 68.19 & 87 & 79 \\
\hline 4 & 6.54 & 30.46 & 15.88 & 9.64 & 3.39 & 59.38 & 95 & 80 \\
\hline 5 & 6.56 & 31.48 & 15.60 & 10.47 & 3.82 & 61.36 & 87 & 65 \\
\hline 6 & 6.56 & 34.89 & 17.55 & 11.36 & 4.50 & 68.30 & 90 & 55 \\
\hline 7 & 6.55 & 25.96 & 12.92 & 7.97 & 3.16 & 50.01 & 89 & 64 \\
\hline 8 & 6.55 & 27.86 & 13.71 & 8.34 & 3.37 & 53.27 & 90 & 63 \\
\hline 9 & 6.56 & 34.27 & 16.26 & 11.12 & 4.24 & 65.89 & 101 & 75 \\
\hline 10 & 6.55 & 34.95 & 17.49 & 11.03 & 4.49 & 67.96 & 102 & 77 \\
\hline 11 & 6.57 & 27.51 & 13.06 & 8.48 & 3.55 & 52.60 & 96 & 74 \\
\hline 12 & 6.55 & 33.23 & 16.94 & 10.31 & 3.72 & 64.21 & 94 & 76 \\
\hline 13 & 6.56 & 34.08 & 17.27 & 10.44 & 3.98 & 65.76 & 85 & 63 \\
\hline 14 & 6.56 & 35.33 & 17.64 & 10.92 & 4.53 & 68.42 & 84 & 61 \\
\hline 15 & 6.55 & 35.51 & 17.28 & 10.47 & 4.39 & 67.66 & 85 & 58 \\
\hline Regression probability & 0.201 & 0.021 & 0.006 & 0.001 & 0.081 & 0.010 & 0.269 & 0.003 \\
\hline Regression $\mathrm{R}^{2}(\%)$ & 79.7 & 92.9 & 95.9 & 98.3 & 87.0 & 94.8 & 76.4 & 96.9 \\
\hline
\end{tabular}

${ }^{1} \mathrm{C} 2$, acetate; $\mathrm{C}$, propionate; $\mathrm{C} 4$, butyrate; $\mathrm{C}$, valerate.

constructed and applied: i) low vs high energy; ii) additive vs no additive; iii) contrast 1 vs contrast 2 . Ruminal $\mathrm{pH}$, $\mathrm{NH}_{3}-\mathrm{N}$ and VFA, rumen temperature and rectal temperature determined at several fixed times after feeding, were analysed using the REPEATED statement with the PROC MIXED of SAS. The following model was used; response = overall mean+steer+period+treatment+time+treatment $\times$ time +error term. Steer $\times$ period $\times$ treatment were used as the subject. The same contrast statements as noted earlier were used to partition the treatment sum of squares.

\section{RESULTS}

\section{Experiment 1}

Fifteen runs were prepared according to the Box Behnken design, and three variables were incorporated into the diet with different ratios as shown in Table 1. Ruminal $\mathrm{pH}$, VFA production and biogas production were measured at the end of every incubation time period. The results of responses assigned to runs are summarized in Table 3 with their regression probabilities. Significances in regression were detected for acetic acid, propionic acid, butyric acid and total VFA production at $24 \mathrm{~h}$ incubation and biogas production at $12 \mathrm{~h}$ incubation $(\mathrm{p}<0.05)$. Analysis of variance was performed on total VFA and propionic acid production at $24 \mathrm{~h}$ incubation and biogas production at $12 \mathrm{~h}$ incubation. Results of ANOVA for total VFAs and propionic acid production and biogas production are summarized in Table 4. In total VFA production, significance in regression denoted $(\mathrm{p}=0.010)$ that used variables significantly influenced, and it was determined that observed responses were fitted well by the non-significance at lack-of-fit ( $\mathrm{p}=$ 0.190). In the effects of variables, only the interaction showed significance $(p=0.033)$. For propionic acid production, significant effects were detected in regression $(\mathrm{p}=0.006)$ and interaction $(\mathrm{p}=0.021)$. The significances of regression and lack-of-fit in biogas production were 0.003 and 0.483 , respectively. In the effects of variables, significant effects were found in linear $(p=0.001)$ and square $(p=0.001)$ effects. The patterns of interaction for total VFA and propionic acid productions between variables based on the significance of interaction in ANOVA were investigated (Figure 1). The responses of total VFA and propionic acid productions for variables were very similar each other. When protected fat and choline were mixed in diet with around $0.05 \%$ and $0.01 \%$, respectively, it showed the greatest total VFA (Figure 1A) and propionic acid productions (Figure 1D). Distinct interaction was found in the interaction between yeast culture and protected fat and the greatest total VFAs and propionic acid productions were detected at the point where $0.025 \%$ yeast culture and $0.05 \%$ of protected were mixed (Figure $1 \mathrm{~B}$ and $1 \mathrm{E}$ ). The greatest total VFA production was detected at $0.015 \%$ of yeast culture with $0.001 \%$ or less of choline (Figure 1C). In propionic acid production, however, $0.005 \%$ of choline and $0.02 \%$ of yeast culture showed the greatest production (Figure 1F). The effect of variables on biogas production was figured using quadratic equations since its significances was found only in linear and square effects in result of ANOVA. The lowest gas production was detected at $0.05 \%$ 
Table 4. Analysis of variance results of regressions for total VFAs at $24 \mathrm{~h}$ incubation and biogas production at $12 \mathrm{~h}$ incubation

\begin{tabular}{|c|c|c|c|c|c|c|}
\hline Response & Source & Degree of freedom & Sum of square & Mean of square & f-value & p-value \\
\hline \multirow[t]{8}{*}{ Total VFAs at $24 \mathrm{~h}$} & Regression & 9 & 523.11 & 58.12 & 10.13 & 0.010 \\
\hline & Linear & 3 & 367.83 & 7.79 & 1.36 & 0.356 \\
\hline & Square & 3 & 38.40 & 10.61 & 1.85 & 0.256 \\
\hline & Interaction & 3 & 116.88 & 38.96 & 6.79 & 0.033 \\
\hline & Residual error & 5 & 28.69 & 5.74 & - & - \\
\hline & Lack-of-fit & 3 & 24.93 & 8.31 & 4.43 & 0.190 \\
\hline & Pure error & 2 & 3.75 & 1.88 & - & - \\
\hline & Total & 14 & 551.80 & - & - & - \\
\hline \multirow[t]{8}{*}{ Propionate at $24 \mathrm{~h}$} & Regression & 9 & 35.54 & 3.95 & 13.07 & 0.006 \\
\hline & Linear & 3 & 23.82 & 0.88 & 2.93 & 0.139 \\
\hline & Square & 3 & 4.03 & 1.12 & 3.72 & 0.096 \\
\hline & Interaction & 3 & 7.69 & 2.56 & 8.49 & 0.021 \\
\hline & Residual error & 5 & 1.51 & 0.30 & - & - \\
\hline & Lack-of-fit & 3 & 1.42 & 0.47 & 10.66 & 0.087 \\
\hline & Pure error & 2 & 0.09 & 0.04 & - & - \\
\hline & Total & 14 & 37.06 & - & - & - \\
\hline \multirow{8}{*}{$\begin{array}{l}\text { Biogas production } \\
\text { at } 12 \mathrm{~h}\end{array}$} & Regression & 9 & 1113.36 & 123.71 & 17.39 & 0.003 \\
\hline & Linear & 3 & 256.48 & 255.02 & 35.85 & 0.001 \\
\hline & Square & 3 & 829.79 & 280.32 & 39.40 & 0.001 \\
\hline & Interaction & 3 & 27.10 & 9.03 & 1.27 & 0.379 \\
\hline & Residual error & 5 & 35.57 & 7.11 & - & - \\
\hline & Lack-of-fit & 3 & 22.90 & 7.64 & 1.21 & 0.483 \\
\hline & Pure error & 2 & 12.67 & 6.33 & - & - \\
\hline & Total & 14 & 1148.93 & - & - & - \\
\hline
\end{tabular}

VFA, volatile fatty acid.

$\mathrm{R}^{2}$ values for total VFAs, propionic acid and biogas production were $94.8 \%, 95.9 \%$, and $96.9 \%$, respectively.

of protected fat (Figure 2A) and $0.005 \%$ of choline (Figure 2C). Biogas production showed a pattern to be increased along with increased yeast culture content in diet until $0.04 \%$ and then it was declined (Figure 2B). Optimizing blending condition of protected fat, choline and yeast culture was performed with three targets, maximizing total VFA and propionic acid productions at $24 \mathrm{~h}$ and minimizing biogas production at $12 \mathrm{~h}$, using response surface modelling. As a result, a blending condition of $0.05 \%$ of protected fat, $0.005 \%$ of choline and $0.025 \%$ of yeast culture was obtained and subsequently an additive composed of $50 \%$ of protected fat, $25 \%$ of yeast culture, $5 \%$ of choline, $7 \%$ of organic zinc, $6.5 \%$ of cinnamon and $6.5 \%$ of stevioside was prepared. The optimized additive predicted $36.19 \mathrm{mM}$ of total VFAs and $20.15 \mathrm{mM}$ of propionic acid productions at $24 \mathrm{~h}$ and $27.65 \mathrm{~mL}$ of biogas production at $12 \mathrm{~h}$.

The simulated optimum blending condition of the additive was verified through an in vitro experiment. Two treatments were used: control (no additive) and treatment (optimum blending with fixed variables). All in vitro experiment procedures and conditions were the same with those in the optimization experiment. The results from the verification experiment were summarized in Table 5. Significant differences between control and treatment were found in $\mathrm{NH}_{3}-\mathrm{N}$, total VFA, acetate, butyrate, valerate and biogas production $(\mathrm{p}<0.05)$. Those in treatment were lower than the control. In overall effects across the treatment and incubation time, all parameters indicated significant effects of treatment and incubation time $(\mathrm{p}<0.01)$. The significant interactions between treatment and incubation time were detected at $\mathrm{pH}, \mathrm{NH}_{3}-\mathrm{N}$, total VFA, acetate and propionate $(p<0.05)$.

\section{Experiment 2}

Feed intake, feces and urine output: The effect of energy level and inclusion of additive on feed intake, feces and urine outputs are summarized in Table 6. Different energy levels and adding additive in the diet did not influence feed intake $(\mathrm{p}>0.05)$. There was no interaction between energy level and additive inclusion ( $p>0.05)$.

Rumen parameters: Rumen parameters in different treatments are summarized in Table 7. Significant effect of variation of energy levels and inclusion of additive on ruminal $\mathrm{pH}$ was found $(\mathrm{p}=0.007)$. Feed energy levels significantly influenced on ruminal $\mathrm{pH}(\mathrm{p}=0.001)$, whereas no significant effect of additive $(\mathrm{p}=0.55)$ and the interaction between energy levels and additive $(p=0.397)$ were detected as not significant. Total VFAs production was 
(A)

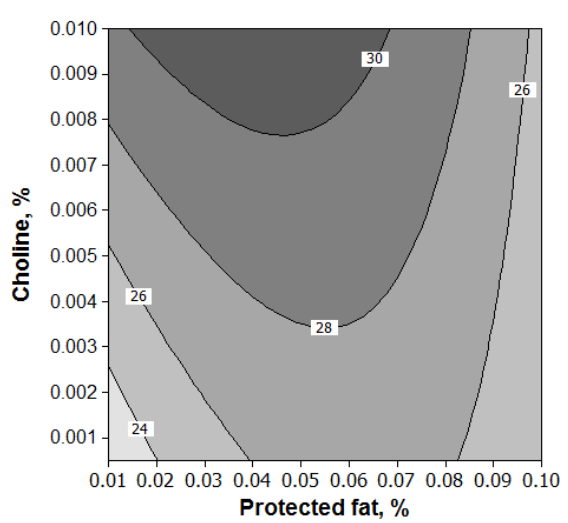

(B)

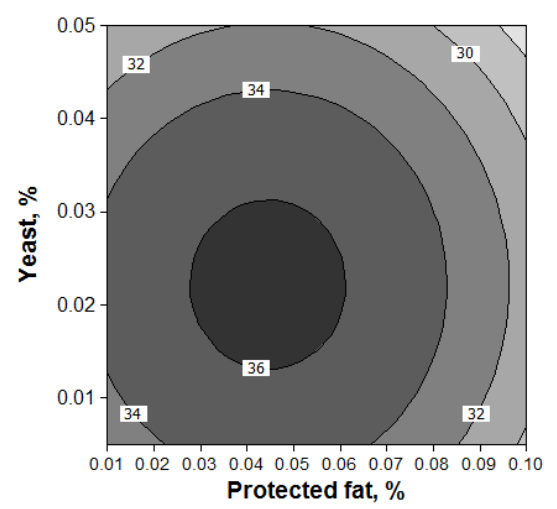

(C)

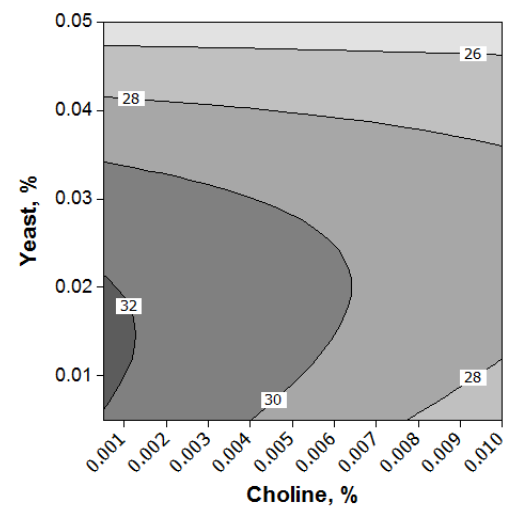

(D)

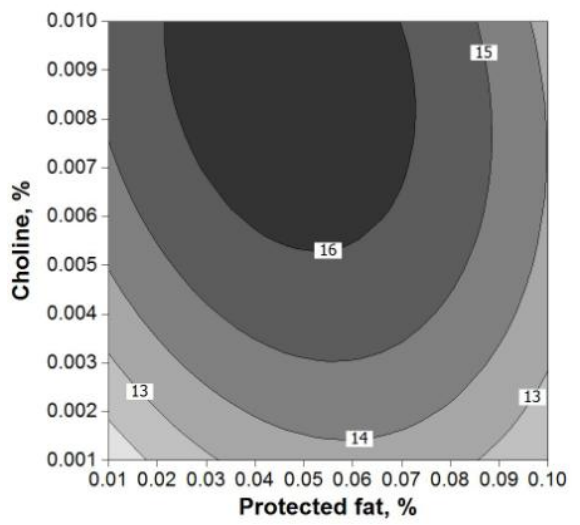

(E)

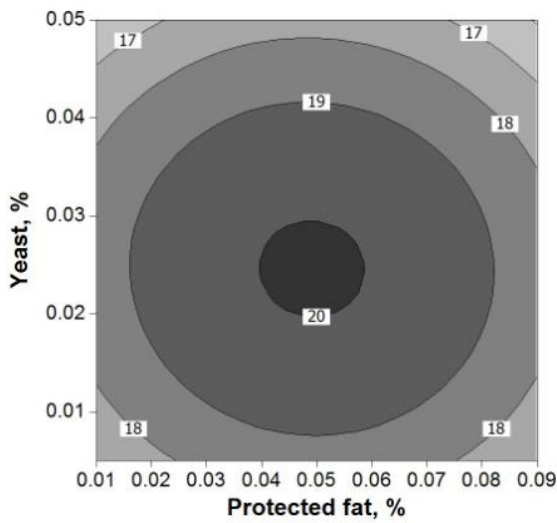

(F)

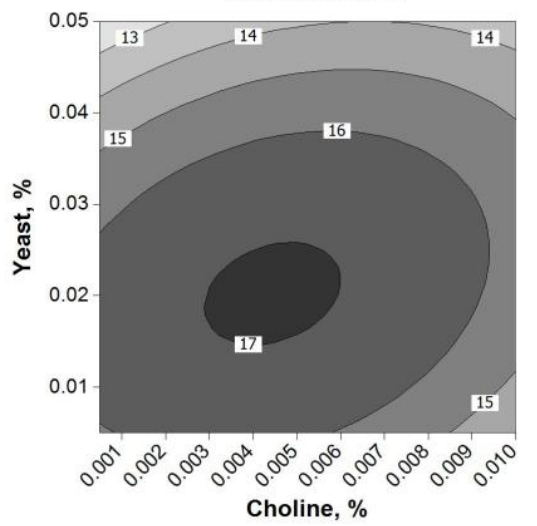

Figure 1. Interactions among variables on total volatile fatty acid (A, B, C) and propionic acid (D, E, F) production at $24 \mathrm{~h}$ incubation of in vitro rumen fermentation. Each remaining variable was fixed at center point: yeast $(0.055 \%)$ in $\mathrm{A}$ and $\mathrm{D}$, protected fat $(0.11 \%)$ in $\mathrm{B}$ and $\mathrm{E}$, and choline $(0.0084 \%)$ in $\mathrm{C}$ and $\mathrm{F}$.
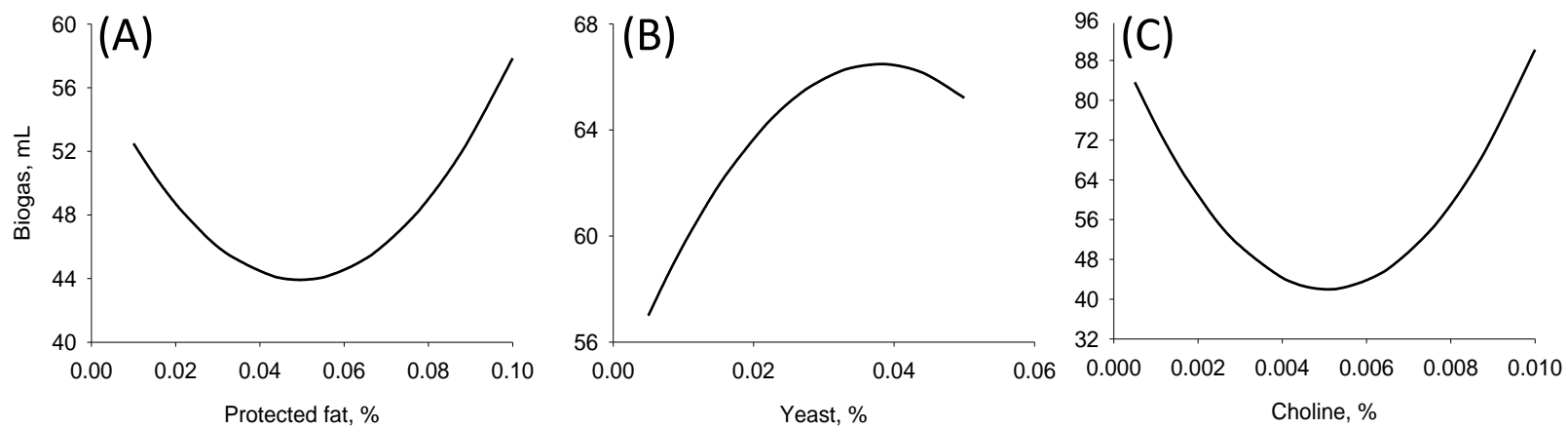

Figure 2. Effect of different levels of (A) protected fat, (B) yeast, and (C) choline in diet on biogas production from in vitro rumen fermentation at $12 \mathrm{~h}$ incubation. Biogas production was calculated by regression. 
Table 5. Rumen fermentation parameters with optimized additives

\begin{tabular}{|c|c|c|c|c|c|c|c|c|}
\hline \multirow{2}{*}{ Items } & \multicolumn{5}{|c|}{ Rumen parameter at $24 \mathrm{~h}$ incubation } & \multicolumn{3}{|c|}{ Overall effect $^{1}$} \\
\hline & Control & Treatment & SE & t-value & $\mathrm{p}$-value & Treatment & Time & Interaction \\
\hline $\mathrm{pH}$ & 6.78 & 6.85 & 0.028 & -2.575 & 0.062 & $<0.001$ & $<0.001$ & $<0.001$ \\
\hline $\mathrm{NH}_{3}-\mathrm{N}(\mathrm{mg} / 100 \mathrm{~mL})$ & 7.22 & 2.33 & 0.324 & 15.107 & $<0.001$ & $<0.001$ & $<0.001$ & 0.001 \\
\hline Biogas production $^{2}(\mathrm{~mL})$ & 45.33 & 36.67 & 1.886 & 4.596 & 0.010 & $<0.001$ & $<0.001$ & 0.066 \\
\hline Total VFAs (mM) & 51.10 & 40.88 & 2.229 & 4.587 & 0.010 & $<0.001$ & $<0.001$ & 0.008 \\
\hline Acetate $(\mathrm{mM})$ & 32.26 & 26.47 & 1.393 & 4.157 & 0.014 & $<0.001$ & $<0.001$ & 0.037 \\
\hline Propionate $(\mathrm{mM})$ & 9.87 & 7.80 & 0.807 & 2.568 & 0.931 & $<0.001$ & $<0.001$ & 0.004 \\
\hline Butyrate (mM) & 7.45 & 5.52 & 0.303 & 6.341 & 0.003 & $<0.001$ & $<0.001$ & 0.147 \\
\hline Valerate $(\mathrm{mM})$ & 1.53 & 1.09 & 0.089 & 4.869 & 0.008 & $<0.001$ & $<0.001$ & 0.156 \\
\hline
\end{tabular}

SE, standard error; VFA, volatile fatty acid.

${ }^{1}$ Significances for overall effect was calculated using results at $0,2,4,6,8,12,24$, and 48 h incubation.

${ }^{2}$ Biogas production results were from $12 \mathrm{~h}$ incubation.

Table 6. Effect of experimental diets on feed intake, feces and urine output

\begin{tabular}{|c|c|c|c|c|c|c|c|c|}
\hline \multirow[b]{2}{*}{ Parameter } & \multicolumn{4}{|c|}{ Treatment diets $^{1}$} & \multirow[b]{2}{*}{ p-value } & \multicolumn{3}{|c|}{ p-value } \\
\hline & $6: 4^{-}$ & $4: 6^{-}$ & $6: 4^{+}$ & $4: 6^{+}$ & & Energy level & Additive & $\begin{array}{c}\text { Energy level } \\
\text { xadditive }\end{array}$ \\
\hline Feed intake & $7.78 \pm 0.02$ & $7.92 \pm 0.05$ & $7.95 \pm 0.03$ & $7.78 \pm 0.11$ & 0.678 & 0.531 & 0.373 & 0.653 \\
\hline Feces & $10.61 \pm 0.34$ & $9.42 \pm 0.32$ & $11.06 \pm 0.58$ & $9.39 \pm 0.82$ & 0.406 & 0.799 & 0.121 & 0.769 \\
\hline Urine & $8.32 \pm 0.79$ & $7.09 \pm 1.25$ & $9.46 \pm 0.89$ & $4.73 \pm 0.76$ & 0.423 & 0.764 & 0.176 & 0.401 \\
\hline
\end{tabular}

${ }^{1} 6: 4$ and 4:6 stand for low and high energy level diets; ${ }^{+}$and ${ }^{-}$stand for presence or absence of dietary feed additive, respectively.

Values are mean \pm standard error of the mean $(n=4)$.

found to be not influenced by the energy in diet and adding additive, significantly $(\mathrm{p}=0.327)$. However, individual VFA production was influenced by treatment $(p<0.05)$. Significant effects of treatments were found in acetate, propionate, $n$-valerate and $\mathrm{A} / \mathrm{P}$ ratio $(\mathrm{p}<0.05)$. Significant effect of energy treatment in diet was detected in acetate ( $p$ $=0.024)$, propionate $(\mathrm{p}=0.022)$, $\mathrm{n}$-valerate $(\mathrm{p}<0.001)$ and acetate:propionate $(\mathrm{A} / \mathrm{P})$ ratio $(\mathrm{p}<0.001)$. The additive showed significant effect of additive in propionate $(\mathrm{p}=$ $0.002)$, iso-butyrate $(\mathrm{p}=0.044)$, $\mathrm{n}$-valerate $(\mathrm{p}=0.001)$ production and the $\mathrm{A} / \mathrm{P}$ ratio $(\mathrm{p}=0.004)$. Significant interaction between energy level and additive was found in acetate $(\mathrm{p}=0.037)$, n-butyrate $(\mathrm{p}=0.031), \mathrm{n}$-valerate $(\mathrm{p}=$
$0.001)$ production and the $\mathrm{A} / \mathrm{P}$ ratio $(\mathrm{p}=0.002)$. Greater acetate productions were detected in low energy diet treatments regardless of including additive. Increasing energy level in diet elevated propionate production and those increments were greater when additive was included in diet than the treatment without additive. Two parameters, $\mathrm{n}$-valerate and $\mathrm{A} / \mathrm{P}$ ratio, were detected as mostly influenced. It was found that energy level could increase n-valerate production and this increment also could be greater by adding additive. High energy resulted low in A/P ratio and the difference of $\mathrm{A} / \mathrm{P}$ ratio between low and high energy levels was raised by the use of additive. Treatment influenced $\mathrm{NH}_{3}-\mathrm{N}$ production significantly $(\mathrm{p}=0.007)$.

Table 7. Effect of experimental diets on ruminal parameters

\begin{tabular}{|c|c|c|c|c|c|c|c|c|}
\hline \multirow[b]{2}{*}{ Parameter } & \multicolumn{4}{|c|}{ Treatment diets $^{1}$} & \multirow[b]{2}{*}{ p-value } & \multicolumn{3}{|c|}{ p-value } \\
\hline & $6: 4^{-}$ & $4: 6^{-}$ & $6: 4^{+}$ & $4: 6^{+}$ & & $\begin{array}{c}\text { Energy } \\
\text { level }\end{array}$ & Additive & $\begin{array}{l}\text { Energy level } \\
\text { xadditive }\end{array}$ \\
\hline $\mathrm{pH}$ & $6.45 \pm 0.05$ & $6.32 \pm 0.07$ & $6.46 \pm 0.08$ & $6.25 \pm 0.09$ & 0.007 & 0.001 & 0.550 & 0.397 \\
\hline $\mathrm{NH}_{3}-\mathrm{N}(\mathrm{mg} / 100 \mathrm{~mL})$ & $6.88 \pm 1.17$ & $4.07 \pm 1.15$ & $5.99 \pm 0.93$ & $6.45 \pm 1.33$ & 0.007 & 0.051 & 0.211 & 0.007 \\
\hline Total VFA (mM) & $85.65 \pm 3.49$ & $86.70 \pm 3.63$ & $90.98 \pm 3.35$ & $84.73 \pm 3.71$ & 0.327 & 0.312 & 0.512 & 0.157 \\
\hline Acetate $(\mathrm{mM})$ & $60.30 \pm 2.27$ & $59.96 \pm 2.34$ & $64.47 \pm 2.27$ & $56.14 \pm 2.43$ & 0.026 & 0.024 & 0.925 & 0.037 \\
\hline Propionate (mM) & $13.50 \pm 0.69$ & $13.90 \pm 0.78$ & $14.35 \pm 0.67$ & $16.40 \pm 1.11$ & 0.011 & 0.022 & 0.002 & 0.119 \\
\hline iso-butyrate $(\mathrm{mM})$ & $0.78 \pm 0.05$ & $0.74 \pm 0.07$ & $0.71 \pm 0.05$ & $0.62 \pm 0.04$ & 0.089 & 0.145 & 0.044 & 0.521 \\
\hline n-butyrate (mM) & $9.21 \pm 0.51$ & $9.90 \pm .51$ & $9.55 \pm 0.46$ & $9.81 \pm 0.57$ & 0.113 & 0.934 & 0.253 & 0.031 \\
\hline iso-valerate $(\mathrm{mM})$ & $0.98 \pm 0.06$ & $1.13 \pm 0.07$ & $1.03 \pm 0.06$ & $1.01 \pm 0.05$ & 0.115 & 0.147 & 0.461 & 0.067 \\
\hline n-valerate $(\mathrm{mM})$ & $0.88 \pm 0.05$ & $1.06 \pm 0.09$ & $0.86 \pm 0.04$ & $1.75 \pm 0.24$ & $<0.001$ & $<0.001$ & 0.001 & 0.001 \\
\hline $\mathrm{A} / \mathrm{P}$ ratio & $4.53 \pm 0.08$ & $4.40 \pm 0.11$ & $4.55 \pm 0.10$ & $3.68 \pm 0.25$ & $<0.001$ & $<0.001$ & 0.004 & 0.002 \\
\hline
\end{tabular}

VFA, volatile fatty acid; $\mathrm{A} / \mathrm{P}$, acetate/propionate.

${ }^{1} 6: 4$ and 4:6 stand for low and high energy level diets; ${ }^{+}$and $^{-}$stand for presence or absence of dietary feed additive, respectively.

Values are mean \pm standard error of the mean $(n=4)$. 
Table 8. Effect of experimental diets on rumen and rectal temperature

\begin{tabular}{|c|c|c|c|c|c|c|c|c|}
\hline \multirow[b]{2}{*}{ Parameter } & \multicolumn{4}{|c|}{ Treatment diets $^{1}$} & \multirow[b]{2}{*}{ p-value } & \multicolumn{3}{|c|}{$\mathrm{p}$-value } \\
\hline & $6: 4^{-}$ & $4: 6^{-}$ & $6: 4^{+}$ & $4: 6^{+}$ & & $\begin{array}{c}\text { Energy } \\
\text { level }\end{array}$ & Additive & $\begin{array}{c}\text { Energy level } \\
\times \text { additive }\end{array}$ \\
\hline Rumen $\left({ }^{\circ} \mathrm{C}\right)$ & $38.33 \pm 0.05$ & $38.63 \pm 0.04$ & $38.31 \pm 0.03$ & $38.21 \pm 0.04$ & $<0.001$ & 0.235 & 0.009 & 0.004 \\
\hline $\operatorname{Rectal}\left({ }^{\circ} \mathrm{C}\right)$ & $39.47 \pm 0.08$ & $39.48 \pm 0.14$ & $39.23 \pm 0.05$ & $39.28 \pm 0.07$ & $<0.001$ & 0.449 & $<0.001$ & 0.658 \\
\hline
\end{tabular}

${ }^{1} 6: 4$ and 4:6 stand for low and high energy level diets; ${ }^{+}$and ${ }^{-}$stand for presence or absence of dietary feed additive, respectively.

Values are mean \pm standard error of the mean $(n=4)$.

Effects of energy levels in diet and additive were not significant $(p>0.05)$ and the interaction between those was significant $(\mathrm{p}=0.007)$. There was interaction between feed energy level and supplementation of additive.

Rumen and rectal temperature: The internal body temperature is a more reliable indicator of an animal's thermal balance (Shearer and Beede, 1990). Overall rumen and rectal temperature in a day for each treatment are summarized in Table 8 . Treatments significantly influenced rumen and rectal temperature $(\mathrm{p}<0.001)$. Feed energy level in diet did not influence rumen $(\mathrm{p}=0.235)$ or rectum $(\mathrm{p}=$ $0.449)$ temperature. Whereas, additive did significant effect on each temperature $(\mathrm{p}=0.009)$. Interaction of energy level in diet and additive was significant only in rumen temperature $(p=0.004)$. Increasing energy level in the diet not supplemented with the additive elevated rumen temperate from $38.33^{\circ} \mathrm{C}$ to $38.63^{\circ} \mathrm{C}$ but when the same diet was supplemented with the additive, rumen temperature declined from $38.31^{\circ} \mathrm{C}$ to $38.21^{\circ} \mathrm{C}$. The changes of temperature in the rumen and rectum were relatively lower than the rumen. Rumen and rectal temperatures are represented in Figure 3. Rumen temperatures for the $4: 6^{-}$ diet were higher than others until $-7 \mathrm{~h}$ before morning feeding time and this pattern tended to be reversed afterwards. After morning feeding, the $6: 4^{-}$showed the highest rumen temperature. Interestingly, supplementation using diet with additive, regardless of energy level, resulted in lower rumen and rectal temperatures when compared to non-supplemented diets (Figure 3A, B).

\section{DISCUSSION}

Providing high energy diet is an important feeding strategy for beef cattle during the fattening period. However, this strategy can cause an elevation of internal body temperature and let the beef cattle exposure to heat stress, particularly during hot summer season. Negative effects associated with heat stress include suppression of appetite and intake and it can result in a decline of productivity (Mader et al., 2002; Mader and Davis, 2004). The present study investigated the optimum blending of protected fat, choline and yeast culture for an effective additive in reducing internal body temperature and determined its effect. Optimization of blending was conducted using fractional factorial design and response surface modeling and it was calculated based on maximizing VFA production and minimizing biogas production. The optimized additive reduced rumen and rectal temperatures without suppressing feed intake. This suggests that its mode of action is not associated with a suppressed dry matter intake. Generally, animals reduce DMI under hot environments as a way of trying to bring their metabolic heat production in line with their heat dissipation mechanism (Gaughan et al., 2002). The ambient temperature at which ruminants begin to reduce dry matter intake is $30^{\circ} \mathrm{C}$ at a relative humidity below $80 \%$ (Bernabucci et al., 2010). The normal rectal
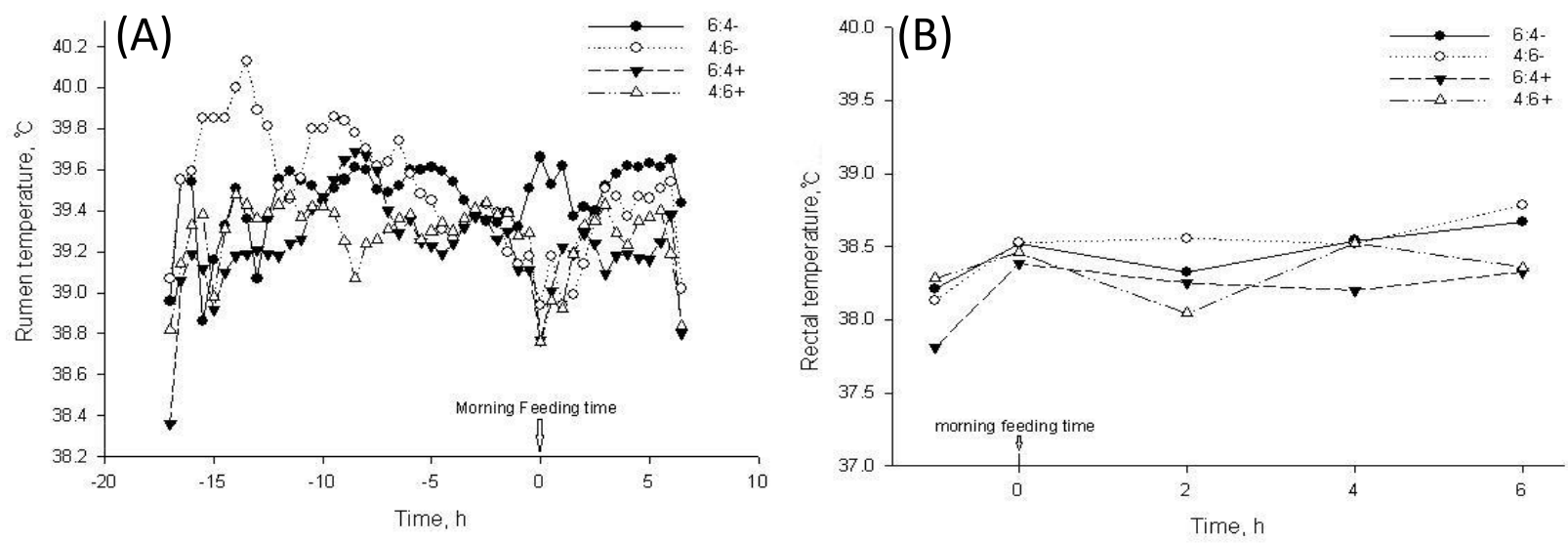

Figure 3. The effect of treatment diets on rumen (A) and rectal (B) temperature patterns. In treatment, 6:4 and 4:6 stand for low and high energy level diets; ${ }^{+}$and ${ }^{-}$stand for presence or absence of dietary feed additive, respectively. 
temperature is $38 \pm 0.5^{\circ} \mathrm{C}$ (Shearer and Beede, 1990). In the present study, higher rectal temperatures were observed, indicating the experimental environment conditions were effective in inducing excessive heat load. The rumen temperature was lower than the rectal temperature as is expected. Rumen temperatures are rated as more reliable than rectal temperatures (Shearer and Beede, 1990). The observed interaction between energy levels and additive in rumen temperature demonstrated that the additive was more effective in reducing rumen temperature when included in the high energy level diet. The observed reduction in excessive body heat load when diets were supplemented with feed additive may be attributed to; firstly, prevalence of more energy-efficient pathways (Russell, 2007). In the current study, supplementation of diets with the additive resulted in greater propionate production. The propionate pathway consumes metabolic hydrogen and hence less hydrogen is lost in the form of methane. This pathway is likely to generate less heat compared to less energy efficient pathways. Methane represents a significant energy loss to the animal of up to $12 \%$ of dietary energy consumed (Johnson and Johnson, 1995). The second possible explanation is a by-pass of ruminal fermentation, which can effectively reduce heat generated during fermentation (Russell, 2007). The additive used in this study contained protected fat. Rumen protection of feedstuffs promotes post-ruminal metabolism of the nutrients. Although in our current study the nutrient flow to post-ruminal sites was not determined, we assume this could, at least, explain the observed reduction in rumen and rectal temperatures. The proportions of the individual VFA and consequently the A/P ration were significantly influenced by either the dietary energy concentration, inclusion of additive and/or the interaction between the two. Low energy diets are high in forage hence higher in cellulose and lower in starch. Cellulolytic bacteria and saccharolytic bacteria are more active under such a feeding regime, resulting in high acetic acid production. In contrast, with high starch diets, more propionic acid is produced by the predominantly amylolytic bacteria population (Owens and Goetsch, 1988). Several components of the additive have previously been observed to increase ruminal propionate production. Researchers have found zinc, especially organic zinc to alter the VFA proportion in favour of propionate (Spears et al., 2004). In a study by Busquet et al. (2005), cinnamon altered VFA proportions, reducing the polar proportions of acetate whilst increasing propionate production. Similar alterations in VFA were observed in this study and the inclusion of cinnamon could explain this outcome. The results of the present study showed a significant interaction between additive and energy level in acetate production $(\mathrm{p}<0.05)$. A reduction in acetate production was observed in the high energy diet after supplementing with the feed additive.
Cardozo et al. (2005) also suggested a significantly lower $\mathrm{A} / \mathrm{P}$ ratio in the high concentrate diets. However, contrary to findings by the same researchers, this study did not show a reduction in $\mathrm{NH}_{3}-\mathrm{N}$ production in high energy diets. Rather, a reduction was recorded in the low energy level diet. Dietary fat has been used to achieve high energy density diets that successfully reduced animal's body heat load (Beede and Shearer, 1991). The high heat increment associated with fiber is related to losses of combustible gases and metabolic heat from adenosine triphosphate (ATP) generation through the oxidation of short chain fatty acids (SCFA). The ATP gains from oxidation of SCFA is less energy efficient than ATP synthesis from the oxidation of glucose (Renaudeau et al., 2012). Fats are also utilized more efficiently compared to carbohydrates and proteins, aiding in the reduction of heat increment (Baldwin et al., 1980). However, dietary fats have traditionally limited to less than $5 \%$ in order to avoid the negative effects on rumen fermentation (Byers and Schelling, 1988). This problem can be overcome by using rumen-protected fats. It was reported that dietary supplementation with choline could improve growth performance of finishing cattle without negatively affecting carcass characteristics (Bryant et al., 1999; Drouillard et al., 1999; Bindel et al., 2000). Bryant et al. (1999) postulated that the improvements could be due to alterations in lipid metabolism and/or transport. This is a possibility considering that Drouillard et al. (1999) observed an interaction between dietary fat and supplemental choline. Yang et al. (2010) also observed that cinnamaldehyde, particularly if included early in the feeding period of feedlot steers, may help promote intake and reduce the effects of heat stress. In this study, the feed additive had no effects on ruminal $\mathrm{NH}_{3}-\mathrm{N}$ production. The forage to concentrate $(\mathrm{F} / \mathrm{C})$ ratio however, tended to affect the rumen $\mathrm{NH}_{3}-\mathrm{N}$ content $(\mathrm{p}=0.0503)$. There was a significant effect of dietary energy level and additive interaction $(\mathrm{p}<0.01)$ on $\mathrm{NH}_{3}-\mathrm{N}$. Adding feed additive in a high energy level diet increased the $\mathrm{NH}_{3}-\mathrm{N}$ output whilst reducing its production in a low energy diet. Essential oils mainly reduce ruminal $\mathrm{NH}_{3}-\mathrm{N}$ production by selectively inhibiting bacteria involved in deamination of excess amino acids. Cinnamon and its products have been shown to selectively inhibit rumen bacteria and hence improve the feed efficiency in the rumen (Yang et al., 2010). It has been noted to reduce deamination by means of selectively inhibiting Prevotella spp. (Ferme et al., 2004). Deamination is another metabolic process that can increase rumen metabolic heat generation (Renaudeau et al., 2012). The additive reduced deamination in the high forage diet whilst promoting protein recycling in the high concentrate diet. Stevioside is another essential oil that has been successfully used as a growth promoter. It is the active compound in stevia, a perennial shrub indigenous to Brazil and Paraguay. 
It was reported to possess anti-microbial properties (Atteh et al., 2008). In a review by Renaudeau et al. (2012), it was noted that fungal culture can alleviate the effects of elevated ambient temperature on ruminants. Yeast are generally classified in the kingdom fungi and hence the addition of yeast culture in the feed additive could have aided in the observed reduction in the core body temperature. Other researchers have suggested that yeast culture is one of the means of manipulating rumen fermentation to improve production performance and fiber digestion (Carro et al., 1992). Possibly of greater biological significance is the observation that yeast culture stimulates the rate of VFA production (Gray and Ryan, 1989). Organic zinc has also been observed to alter VFA proportions (Spears et al., 2004). Other researchers observed that organic zinc, compared to inorganic zinc, improved growth (Spears, 1989) and carcass characteristics (Greene et al., 1988; Spears and Kegley, 2002) of cattle. Although there were significant differences $(\mathrm{p}<0.01)$ between treatments in $\mathrm{pH}$, the observed values were within optimal $\mathrm{pH}$ ranges for rumen bacterial activity (Owens and Goetsch, 1988). High energy diets, which were higher in the concentrate proportion, resulted in lower $\mathrm{pH}$ as expected. They contained highly digestible carbohydrates which result in the production of larger amounts of acids than the rate of their absorption compared to high forage diets (Owens and Goetsch, 1988). An accumulation of the acids results in lower $\mathrm{pH}$ values.

\section{CONCLUSION}

The optimized feed additive reduced ruminal and rectal temperatures without negatively affecting feed intake or ruminal fermentation. This additive may prove beneficial in reducing heat stress in cattle. However, more studies need to be carried out at ambient temperatures higher than $30^{\circ} \mathrm{C}$ and relative humidity higher than $70 \%$ in order to verify the effectiveness of the additive.

\section{ACKNOWLEDGMENTS}

This research was supported by funds from IPET (Institute of Planning and Evaluation for Technology in Food, Agriculture, Forestry and Fisheries) and Cooperative Research Program for Agriculture Science and Technology Development (Project No. PJ007800), Rural Development Administration, Republic of Korea.

\section{REFERENCES}

Atteh, J. O., O. M. Onagbesan, K. Tona, E. Decuypere, J. M. Geuns, and J. Buyse. 2008. Evaluation of supplementary stevia (Stevia rebaudiana, bertoni) leaves and stevioside in broiler diets: Effects on feed intake, nutrient metabolism, blood parameters and growth performance. J. Anim. Physiol. Anim. Nutr. 92:640-649.

Baldwin, R. L., N. E. Smith, J. Taylor, and M. Sharp. 1980. Manipulating metabolic parameters to improve growth rate and milk secretion. J. Anim. Sci. 51:1416-1428.

Beede, D. K. and J. K. Shearer. 1991. Nutritional management of dairy cattle during hot weather. Agric. Pract. 12:5-13.

Bernabucci, B., N. Lacetera, L. H. Baumgard, P. P. Rhoads, B. Ronchi, and A. Nardone. 2010. Metabolic and hormonal acclimation to heat stress in domesticated ruminants. Animal 4:1167-1183.

Bindel, D. J., J. S. Drouillard, E. C. Titgemeyer, R. H. Wessels, and C. A. Loest. 2000. Effects of ruminally protected choline and dietary fat on performance and blood metabolites of finishing heifers. J. Anim. Sci. 78:2497-2503.

Box, G. E. P. and E. W. Behnken. 1960. Some new three level designs for the study of quantitative variables. Technometrics 2:455-475.

Bryant, T. C., J. D. Rivera, M. L. Galyean, G. C. Duff, D. M. Hallford, and T. H. Montgomery. 1999. Effects of dietary level of ruminally protected choline on performance and carcass characteristics of finishing beef steers and on growth and seum metabolites in lambs. J. Anim. Sci. 77:2893-2903.

Busquet, M., S. Calsamiglia, A. Ferret, P. W. Cardozo, and C. Kamel. 2005. Effects of cinnamaldehyde and garlic oil on rumen microbial fermentation in a dual flow continuous culture. J. Dairy Sci. 88:2508-2516.

Byers, F. M. and G. T. Schelling. 1988. Lipids in ruminant nutrition. In: The Ruminant Animal: Digestive Physiology and Nutrition (Ed. D. C Church). Prentice-Hall, Inglewood Cliffs, NJ, USA. pp. 298-310.

Cardozo, P. W., S. Calsamiglia, A. Ferret, and C. Kamel. 2005. Screening for the effects of natural plant extracts at different $\mathrm{pH}$ on in vitro rumen microbial fermentation of a highconentrate diet for beef cattle. J. Anim. Sci. 83:2572-2579.

Carro, M. D., P. Lebzien, and K. Rohr. 1992. Effects of yeast culture on rumen fermentation, digestibitiy and duodenal flow in dairy cows fed a silage based diet. Livest. Prod. Sci. 32: 219-229.

Chaney, A. L. and E. P. Marbach. 1962. Modified reagents for the determination of urea and ammonia. Clin. Chem. 8:130-137.

Drouillard, J. S. and G. L. Kuhl. 1999. Effects of previous grazing nutrition and management on feedlot performance of cattle. J. Anim. Sci. 77(Supp. 2):136-146.

Erwin, W. S., J. Marco, and E. M. Emery. 1961. Volatile fatty acid analysis of blood and rumen fluid by gas chromatography. J. Dairy Sci. 44:1768-1774.

Ferme, D., M. Banjai, S. Calsamiglia, M. Busquet, C. Kamel, and G. Avgustin. 2004. The effects of plant extracts on microbial community structure in a rumen-simulating continuous-culture system as revealed by molecular profiling. Folia Microbiol. (Praha). 49:151-155.

Gaughan, J. B., T. L. Mader, S. M. Holt, G. L. Hahn, and B. A. Young. 2002. Review of current assessment of cattle and microclimate during periods of high heat load. Anim. Prod. Aust. 24:77-80.

Gray, W. R. and J. P. Ryan. 1989. Effect of yeast culture on volatile fatty acid levels in ovine rumen fluid incubated with 
oats, barley and hay. Biochem. Soc. Trans.17:390-392.

Greene, L. W., D. K. Lunt, F. M. Byers, N. K. Chirase, C. E. Richmond, R. E. Knutson, and G. T. Schelling. 1988. Performance and carcass quality of steers supplemented with zinc oxide or zinc methionine. J. Anim. Sci. 66:1818-1823.

Johnson, K. A. and D. E. Johnson. 1995. Methane emissions from cattle. J. Anim. Sci. 73:2483-2492.

Mader, T. L., S. M. Holt, G. L. Hahn, M. S. Davis, and D. E. Spiers. 2002. Feeding strategies for managing heat load in feedlot cattle. J. Anim. Sci. 80:2373-2382.

Mader, T. L. and W. S. Davis. 2004. Effect of management strategies on reducing heat stress of feedlot cattle: Feed and water intake. J. Anim. Sci. 82:3077-3087.

McDougall, E. L. 1948. Studies on ruminant saliva. 1. The composition and output of sheep's saliva. Biochem. J. 43:99109.

NRC. 1981. Effect of Environment on Nutrient Requirements of Domestic Animals. National Academy Press, Washington, DC, USA.

Owens, F. N. and A. L. Goetsch. 1988. Ruminal fermentation. In: The Ruminant Animal: Digestive Physiology and Nutrition (Ed. D. C. Church). Prentice-Hall, Englewood Cliffs, NJ, USA. pp. 145-171.

Pompeu, L. B., J. E. Williams, D. E. Spiers, R. L. Weaber, M. R. Ellersieck, K. M. Sargent, N. P. Feyerabend, H. L. Vellios, and F. Evans. 2011. Effect of Ascophyllum nodosum on alleviation of heat stress in dairy cows. Prof. Anim. Sci. 27:181-189.

Renaudeau, D., A. Collin, S. Yahav, V. de Basilio, J. L. Gourdine, and R. J. Collier. 2012. Adaptation to hot climate and strategies to alleviate heat stress in livestock production. Animal 6:707728.
Russell, J. B. 2007. Can the heat of ruminal fermentation be manipulated to decrease heat stress? Proceedings of the 22nd Annual Southwest Nutrition and Management Conference. Vol. 22:109-115.

Ryan, B. 2012. Minitab handbook: updated for release 16. 6thEd. Boston, MA, USA.

Shearer, J. K. and D. K. Beede. 1990. Thermoregulation and physiological responses of dairy cattle in hot weather. Agri Pract. 11:5-17.

Spears, J. W. 1989. Zinc methionine for ruminants: Relative bioavailability of zinc in lambs and effects on growth and performance. J. Anim. Sci. 67:835-843.

Spears, J. W. and E. B. Kegley. 2002. Effect of zinc source (zinc oxide vs. zinc proteinate) and level on performance, carcass characteristics, and immune response of growing and finishing steers. J. Anim. Sci. 80:2747-2752.

Spears, J. W., P. Schlegel, M. C. Seal, and K. E. Lloyd. 2004. Bioavailability of zinc from zinc sulfate and different organic zinc sources and their effects on ruminal volatile fatty acid proportions. Livest. Prod. Sci. 90:211-217.

Spires, D. E., P. A. Eichen, M. J. Leonard, L. E. Wax, G. E. Rottinghaus, J. E. Williams, and D. P. colling. 2004. Benefit of dietary seaweed (Ascophyllum nodosum) extract in reducing heat strain and fescue toxicosis: A comparative study. J. Therm. Biol. 29:753-757.

Williams, J. E., D. E. Spiers, L. N. Thompson-Golden, T. J. Hackman, M. R. Ellersieck, L. Wax, D. P. Colling, J. B. Corners, and P. A. Lancaster. 2009. Effects of Tasco in alleviating heat stress in beef cattle. Prof. Anim. Sci. 25:109117.

Yang, W. Z., B. N. Ametaj, C. Benchaar, M. L. He, and K. A. Beauchemin. 2010. Cinnamaldehyde in feedlot cattle diets: intake, growth performance, carcass characteristics, and blood metabolites. J. Anim. Sci. 88:1082-1092. 